\title{
Transducerless Field Orientation Concepts Employing Saturation-Induced Saliencies in Induction Machines
}

\author{
Patrick L. Jansen and Robert D. Lorenz, Senior Member, IEEE
}

\begin{abstract}
This paper explores the tracking of high-frequency magnetic saliencies created by saturation as a means of continuously estimating the position and magnitude of flux for transducerless field oriented control at zero and low frequency operation. Tracking is based upon inverter-generated high-frequency signal injection with demodulation incorporating heterodyning and a closed-loop tracking filter. Integration of the tracking scheme with the voltage model in a closed-loop flux observer topology is proposed as an attractive means of achieving very wide speed range transducerless field oriented control. The focus is toward induction machines, although the applicability to surfacemounted permanent magnet synchronous machines is also briefly discussed. Experimental evaluation of saturation effects in two induction machines is included, as well as simulation results demonstrating sustained torque control at zero fundamental frequency.
\end{abstract}

Index Terms - Induction motor control, self-sensing control, sensorless contol, sensorless transducerless field orientation, sensorless vector control, transducerless control.

\section{NOMENCLATURE}

\begin{tabular}{|c|c|}
\hline ;"* & $\begin{array}{l}\text { Estimated, commanded quantities, respec- } \\
\text { tively. }\end{array}$ \\
\hline$s$ & Stator reference frame. \\
\hline$r f, s f$ & $\begin{array}{l}\text { Rotor, stator flux reference frames, respe } \\
\text { tively. }\end{array}$ \\
\hline$a$ & Reference frame aligned with saliency. \\
\hline$a$ & Arbitrary turn ratio. \\
\hline $\boldsymbol{i}_{q d s}, \boldsymbol{v}_{q d s}$ & Net stator current and voltage vectors. \\
\hline$\overline{\boldsymbol{i}}_{q d s i}, \boldsymbol{v}_{q d s i}$ & $\begin{array}{l}\text { Signal component stator current and voltag } \\
\text { vectors. }\end{array}$ \\
\hline $\boldsymbol{i}_{q d s 1}, \boldsymbol{v}_{q d s 1}$ & $\begin{array}{l}\text { Fundamental stator current and voltage vec- } \\
\text { tors. }\end{array}$ \\
\hline & Instantaneous rotor, stator current magnitudes. \\
\hline$K$ & Linear controller gains. \\
\hline & Derivative operator. \\
\hline & Injected signal voltage magnitude. \\
\hline
\end{tabular}

Paper IPCSD 96-34, approved by the Industrial Drives Committee of the IEEE Industry Applications Society for presentation at the 1995 IEEE Industry Applications Society Annual Meeting, lake Buena Vista, FL, October 8-12. This work was supported by the National Science Foundation (NSF) and the Wisconsin Electric Machines and Power Electronics Consortium (WEMPEC) of the University of Wisconsin-Madison. Manuscript released for publication May 20, 1996.

P. L. Jansen is with the Power Controls Program, GE Corporate Research \& Development, Schenectady, NY 12301 USA.

R. D. Lorenz is with the Department of Electrical and Computer Engineering, University of Wisconsin, Madison, WI 53706 USA.

Publisher Item Identifier S 0093-9994(96)07067-3.

\author{
$\varepsilon, \varepsilon_{f} \quad$ Unfiltered and filtered heterodyned error sig- \\ nals. \\ $\lambda_{q d s}, \lambda_{q d r} \quad$ Stator and rotor flux linkage vectors. \\ $\lambda_{r}, \lambda_{s} \quad$ Instantaneous rotor and stator flux magnitudes. \\ $\sigma L_{d s}, \sigma L_{q s}$ Stator transient inductances of $d$ - and $q$-axes \\ of saliency. \\ $\tau_{r} \quad$ Rotor time constant: \\ $\theta_{e}, \omega_{e} \quad$ Angular position and velocity of saliency. \\ $\theta_{r f}, \theta_{s f} \quad$ Rotor, stator flux position. \\ $\omega_{i} \quad$ Injected signal frequency. \\ $\omega_{s} \quad$ Slip frequency.
}

\section{INTRODUCTION}

$\mathbf{R}$ OTOR position transducers are commonly used to obtain indirect field oriented control of induction machines in applications requiring robust operation at sustained zero and low fundamental frequency operation. When low-frequency operation is not critical, transducerless field oriented control approaches utilizing the machine back-electromotive force (EMF) are often preferred, thereby avoiding the cost and reliability factors associated with mechanical shaft transducers. Furthermore, near base speed and above, the accuracy of such back-EMF-based field oriented controllers are also capable of being more accurate than the position-transducerbased approaches. The most accurate and robust field oriented systems designed for wide speed range operation presently combine the two approaches in some manner, such as in [1].

A means of estimating rotor position and velocity for transducerless field oriented control (and motion control) capable of sustained zero and low-frequency operation was proposed and demonstrated in [2] and [3]. The approach incorporated two features deemed necessary for accurate and robust estimation independent of speed and load: 1) trackable magnetic saliency, and 2) high-frequency signal injection.

The trackable magnetic saliency was inherent within buried permanent magnet synchronous machines as in [3], but was introduced in induction machines in [2] in the form of a spatial modulation in the rotor leakage inductance. The modulation caused a variation in the stator transient reactance which dominated the stator terminal impedance at high frequencies, thus enabling rotor position (and velocity) to be directly tracked. A balanced three-phase high-frequency signal generated by the inverter and superimposed upon the fundamental enabled tracking independent of speed and load. A closed-loop, 
observer-based heterodyning demodulation scheme provided continuous estimation of both position and velocity.

The concept of a trackable magnetic saliency can be extended to include the tracking of any saliency that causes sufficient variation in the stator transient reactance at high frequencies. One such potentially trackable and useful saliency is that created by saturation in normally nonsalient machines such as standard induction machines and surface-mounted permanent magnet (PM) ac machines. Tracking of a saturationinduced saliency potentially provides flux estimation suitable for transducerless field oriented control at sustained zero and low frequency operation. Such an approach is attractive in applications where torque control (and/or less accurate speed regulation) is required, but not rotor position control.

In [5]-[7], Schroedl demonstrated a method of flux detection based upon such saturation-induced inductance variations in both induction and PM machines. Each phase of a machine was periodically subjected to a test voltage. Flux position was then calculated from the current responses. A Kalman filter was required to provide continuous filtered flux estimates. The applied test voltage interrupted normal torque production and was detrimental to the system performance, especially at higher speeds.

This paper will explore the utilization of saturation-induced saliencies via the tracking scheme of [2] and [3] for obtaining transducerless field oriented control. Simulation results demonstrating zero to medium speed range operation including sustained zero frequency operation are given. A brief section is also devoted to permanent magnet ac machines.

\section{TRACKING OF SALIENCIES}

An approach for tracking of saliencies in the stator transient inductance is outlined in this section. It is a more generalized approach than that presented in [2], which was specific to tracking saliencies in the rotor leakage inductance.

For simplicity, the stator transient inductance is considered as a base quantity characteristic of induction machines, rather than being a secondary quantity derived from leakage and magnetizing inductances as in [2]. The stator transient inductance containing a saturation-induced saliency in the synchronous reference frame can then be represented by

$$
\sigma L_{s}^{e}=\left[\begin{array}{cc}
\sigma L_{q s} & 0 \\
0 & \sigma L_{d s}
\end{array}\right] \text { where } \sigma L_{q s} \neq \sigma L_{d s}
$$

In the stationary (stator) reference frame, the stator transient inductance becomes

$$
\sigma L_{s}^{s}=\left[\begin{array}{cc}
\sigma L_{s 0}+\Delta \sigma L_{s} \cos 2 \theta_{e} & -\Delta \sigma L_{s} \sin 2 \theta_{e} \\
-\Delta \sigma L_{s} \sin 2 \theta_{e} & \sigma L_{s 0}-\Delta \sigma L_{s} \cos 2 \theta_{e}
\end{array}\right]
$$

where $\theta_{e}$ is the angle of the rotating saliency and

$$
\sigma L_{s 0}=\frac{\sigma L_{q s}+\sigma L_{d s}}{2} \quad \Delta \sigma L_{s}=\frac{\sigma L_{q s}-\sigma L_{d s}}{2} .
$$

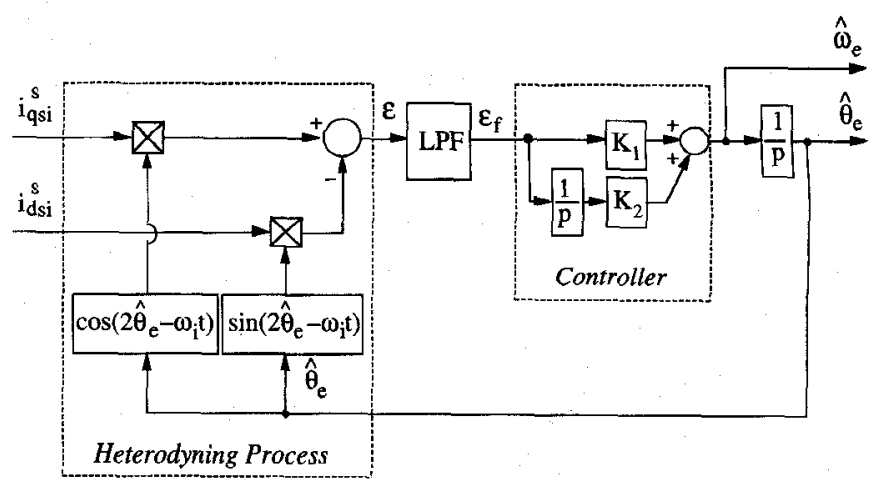

Fig. 1. A closed-loop tracking filter capable of tracking a saliency in the stator transient inductance.

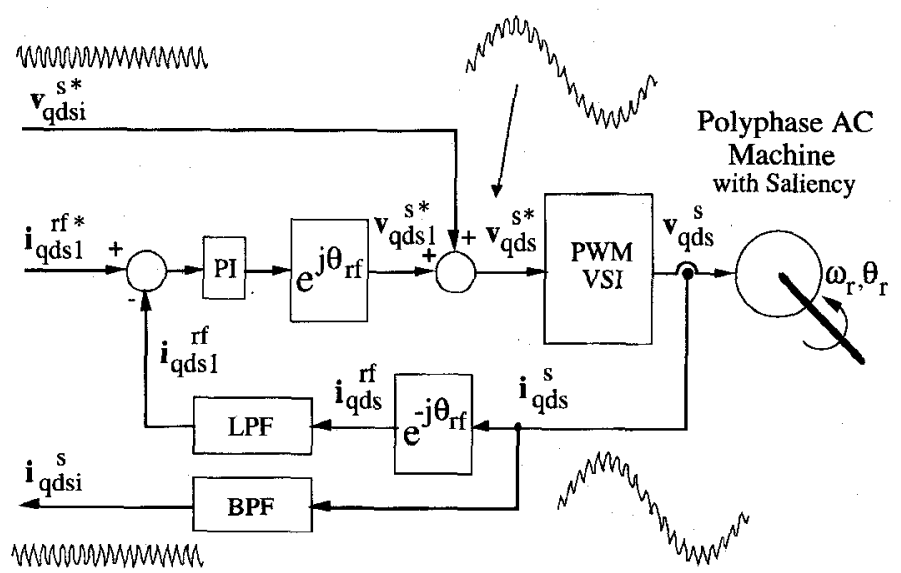

Fig. 2. A high-frequency signal injection scheme utilizing a PWM voltage source inverter (VSI) to synthesize both current-regulated fundamental and low-power high-frequency components.

With the application of a balanced polyphase voltage signal of the form

$$
\boldsymbol{v}_{q d s i}^{s}=\left[\begin{array}{c}
v_{q s i}^{s} \\
v_{d s i}^{s}
\end{array}\right]=V_{s i}\left[\begin{array}{c}
\cos \omega_{i} t \\
-\sin \omega_{i} t
\end{array}\right]
$$

and of sufficiently high frequency such that

$$
\boldsymbol{v}_{q d s}^{s} \approx j \omega_{i} \sigma \boldsymbol{L}_{s}^{s} \boldsymbol{i}_{q d s}^{s}
$$

stator currents will be induced of the form

$$
\boldsymbol{i}_{q d s i}^{s}=\left[\begin{array}{l}
i_{q s i}^{s} \\
i_{d s i}^{s}
\end{array}\right]=\left[\begin{array}{l}
I_{i 0} \sin \omega_{i} t+I_{i 1} \sin \left(2 \theta_{e}-\omega_{i} t\right) \\
I_{i 0} \cos \omega_{i} t+I_{i 1} \cos \left(2 \theta_{e}-\omega_{i} t\right)
\end{array}\right]
$$

where

$$
I_{i 0}=\frac{V_{s i}}{\omega_{i}} \frac{\sigma L_{s 0}}{\sigma L_{s 0}^{2}-\Delta \sigma L_{s}^{2}} \quad I_{i 1}=\frac{V_{s i}}{\omega_{i}} \frac{\Delta \sigma L_{s}}{\sigma L_{s 0}^{2}-\Delta \sigma L_{s}^{2}} .
$$

The second term in both the $q$ - and $d$-axis currents contains useful position information. The coefficient, $I_{i 1}$, is a direct measure of the amount of saliency present.

As in [2] and [3], the spatial information present in the stator currents can be extracted via heterodyning in the form

$$
\varepsilon=i_{q s i}^{s} \cos \left(2 \hat{\theta}_{e}-\omega_{i} t\right)-i_{d s i}^{s} \sin \left(2 \hat{\theta}_{e}-\omega_{i} t\right)
$$

where $\hat{\theta}_{e}$ is the estimated saliency angle in electrical radians. The resulting signal is a single scalar quantity comprised of 


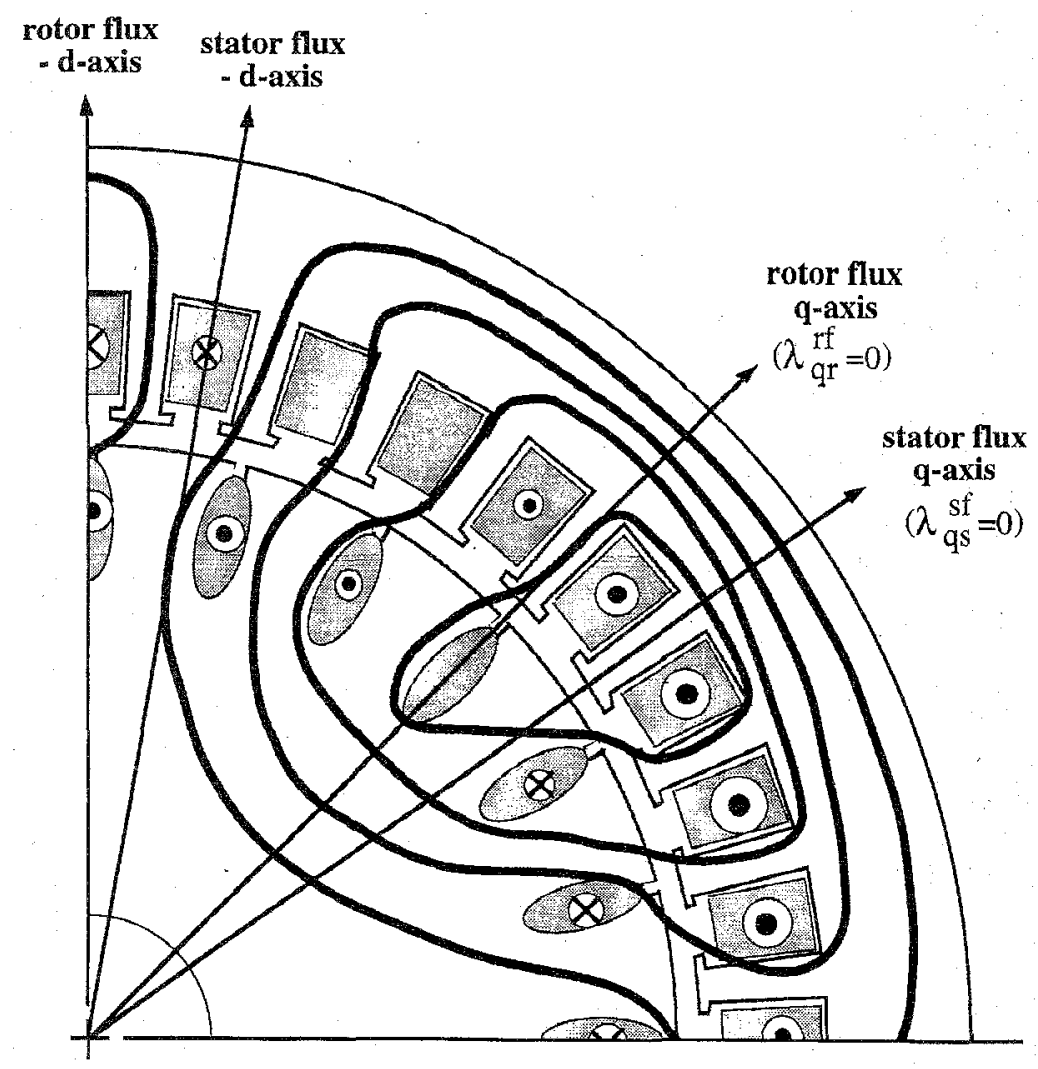

Fig. 3. Illustration of instantaneous fundamental currents and flux paths over one pole of an induction machine with semiclosed rotor slots under loaded operating conditions.

two terms:

$$
\varepsilon=I_{i 0} \sin \left[2\left(\omega_{i} t-\hat{\theta}_{e}\right)\right]+I_{i 1} \sin \left[2\left(\theta_{e}-\hat{\theta}_{e}\right)\right]:
$$

The first term is at frequency $2\left(\omega_{i}-\hat{\omega}_{e}\right)$, where $\hat{\omega}_{e}=p \hat{\theta}_{e}$, and contains no useful information. The second term contains the desirable spatial information and approaches zero as $\hat{\theta}_{e} \rightarrow \theta_{e}$.

By filtering the first term, the remaining term is in the form of a linear position error (as $\hat{\theta}_{e} \rightarrow \theta_{e}$ )

$$
\varepsilon_{f} \approx I_{i 1} \sin \left[2\left(\theta_{e}-\hat{\theta}_{e}\right)\right] \approx 2 I_{i 1}\left(\theta_{e}-\hat{\theta}_{e}\right) .
$$

The error can then be used to drive a closed-loop tracking filter to yield continuous estimates of the saliency position and velocity as shown in Fig. 1 .

Note that the estimation accuracy is independent of the actual inductance and applied signal voltage magnitudes provided that the applied polyphase signal is balanced. The net series resistance neglected in (5) will create a small phase error that can be easily compensated for external to the tracking filter.

As in [2] and [3], the balanced polyphase high-frequency voltage (or current) signal can be generated simultaneous to the machine fundamental excitation via a pulsewidth modulated (PWM) inverter as shown in Fig. 2.

\section{Existence of SATuRATion-INDUCED SALIENCIES}

Saturation effects in induction machines are generally associated with either the main flux created by the magnetizing current, or with localized leakage flux created by slot currents. Both forms of saturation are capable of spatially modulating the stator transient inductance. Likewise, each form can be located predominantly in either the stator or the rotor, and thus impact either the stator or rotor leakage inductances. The extent to which each affects the stator transient inductance is strongly influenced by the type of rotor slotting; i.e., open and semiclosed, or closed rotor slots.

\section{A. Open and Semiclosed Rotor Slot Machines}

Induction machines are commonly designed such that the main flux path is at least partially saturated under rated operation. The stator teeth are typically the most saturated. With open and semiclosed rotor slots, localized saturation near the slot openings is often not significant, particularly in smaller machines.

Fig. 3 illustrates the fundamental component currents and flux paths in an induction machine at one instant of time under loaded operating conditions. Fig. 4 illustrates the currents and flux paths for high (slip) frequency excitation in the same machine. Due to rotor conductor skin effects, the highfrequency flux does not penetrate as deeply into the rotor as does the fundamental component flux. The high-frequency flux and the fundamental component main flux are seen to share similar paths within the stator core and teeth.

Saturation of the main flux path clearly impacts the highfrequency flux path. Since the high-frequency flux paths characterize the stator transient inductance, main flux path 


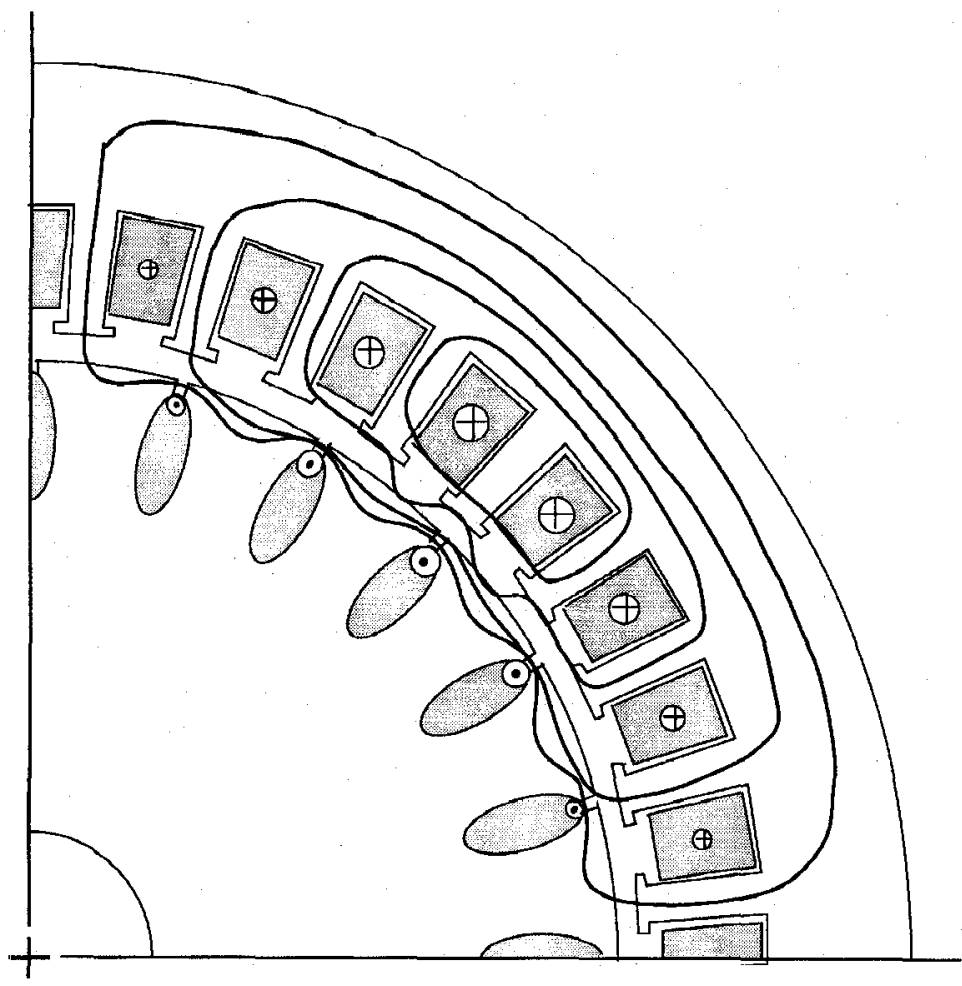

Fig. 4. Illustration of instantaneous high (slip) frequency currents and flux paths over one pole of an induction machine with semiclosed rotor slots.

saturation will also impact the stator transient inductance, creating a spatial modulation aligned with the main flux vector.

Unlike the flux in the stator, the fundamental and highfrequency component fluxes share largely dissimilar paths in the rotor. However, cross-path saturation caused by the main flux near the surface of the rotor teeth will impact the stator transient inductance, further adding to the spatial modulation.

The alignment of the saliency may thus range between that of the stator flux vector and the rotor flux vector. The distinction between the stator and rotor fluxes, and the respective reference frames, is indicated in Fig. 3. Based upon the above considerations, the saliency would be expected to be more closely aligned with the stator flux vector, although it may vary substantially between machine designs and with operating point.

\section{B. Closed Rotor Slot Machines}

In machines with closed rotor slots, saturation of the slot bridges under rated operating conditions can easily reduce the rotor leakage inductance (and thus the stator transient inductance) by a factor of two or more from the unsaturated value. This variation is substantially more than that obtained by saturation in typical open and semiclosed slot machines.

Some saturation of the rotor slot bridge can be expected along the main flux path due to a portion of the flux flowing through the slot bridges as shown in Fig. 5. A spatial modulation or saliency aligned with the main flux would then exist in the high-frequency stator transient inductance under high flux operating conditions while unloaded.
Under loaded operating conditions, rotor current will tend to drive the slot bridges much further into saturation. A larger saliency in the stator transient inductance would then be created that is aligned with the rotor current vector, rather than the main flux. As the space vector diagram in Fig. 6 indicates, the rotor current vector is orthogonal to the rotor flux at steady state. Thus the saliency created by load-induced saturation of the slot bridge will be orthogonal to the saliency created by main flux saturation of the slot bridge.

A machine experiencing an increase in loading from light to heavy under high flux operation could theoretically exhibit a $90^{\circ}$ shift in saliency alignment from the main flux to the rotor current vector. At some operating point, the rotor slot bridges would be uniformly saturated along both the $q$ - and $d$-axes, such that no detectable saliency existed. The tracking of saturation-induced saliencies in closed rotor slot machines thus appears considerably more complex than in open and semiclosed slot machines.

\section{EXPERIMENTAL VERIFICATION OF SATURATION EFFECTS}

The saliency tracking scheme as proposed in Section II was demonstrated in [2] and [3] for machines with fixed saliencies on the rotor. Although rotor position and velocity were the estimated quantities, rather than flux position as proposed in this paper, the approach is equally applicable provided that the saturation-induced saliencies are of sufficient amplitude over the required operating range. Experimental results are thus focused upon the verification of the saturation effects postulated in Section III. 


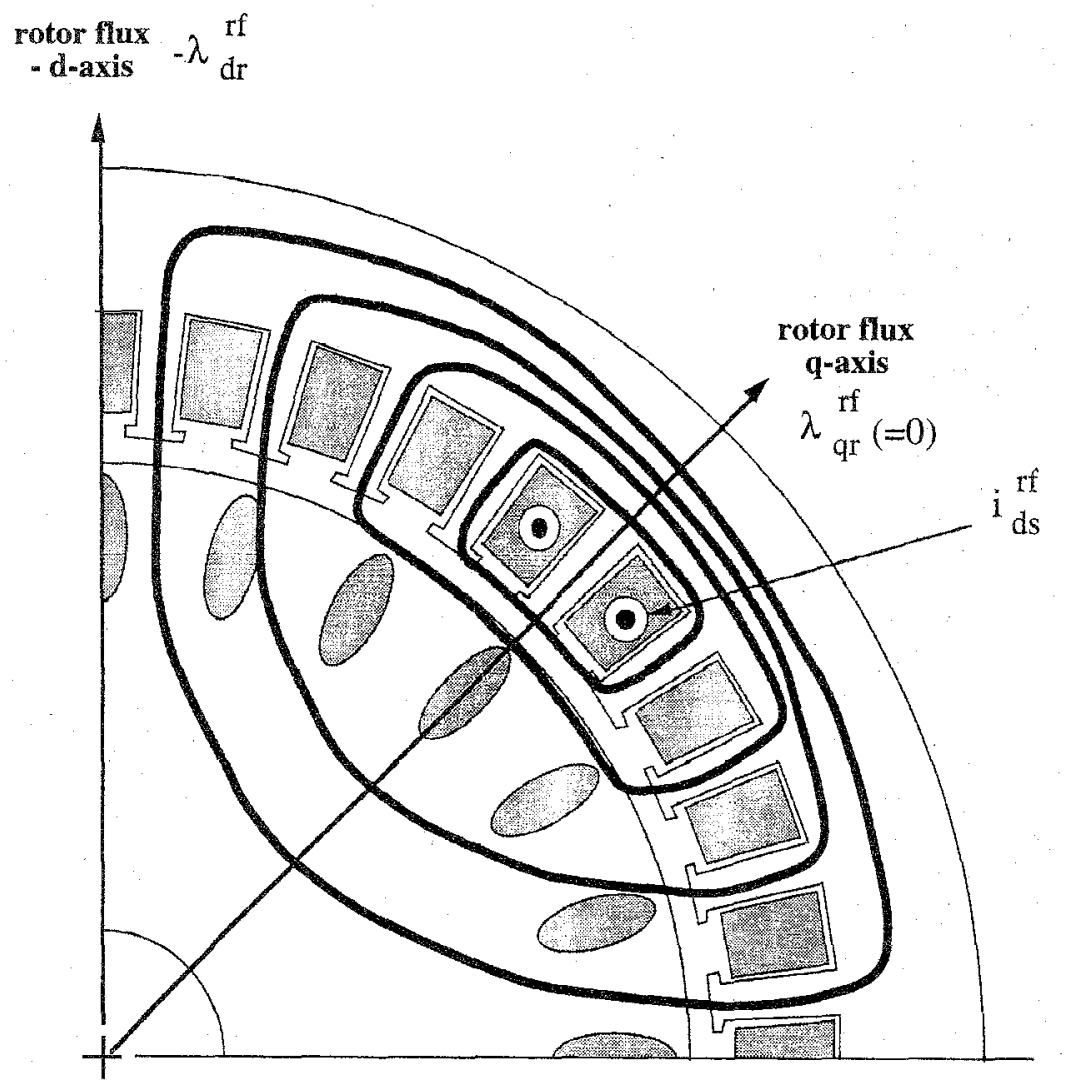

Fig. 5. Flux paths due to magnetizing current, $i_{d s}^{r f}$, in an unloaded closed rotor slot machine at steady state.

\section{A. Semiclosed Rotor Slot Machine}

The locked rotor impedance of a 7.5-hp induction machine (Motor \#1 in Appendix) was measured at $60 \mathrm{~Hz}$. As shown in Fig. 7(a), the stator impedance and corresponding series inductance are essentially independent of the stator (and rotor) current amplitude. For this machine, localized saturation of the slot region caused by fundamental current loading is thus expected to have negligible impact on the stator transient inductance seen at the higher signal frequencies proposed for saliency tracking.

To measure the impact of main flux path saturation, the stator impedance was measured by applying $500-\mathrm{Hz}$ excitation in the stator frame $d$-axis (arbitrarily defined), while magnetizing current was injected in either the $q$ - or $d$-axes. Because the rotor was stationary, the magnetizing current was $\mathrm{dc}$ and no rotor currents were induced except for the $500-\mathrm{Hz}$ signal. As plotted in Fig. 7(b), both a saliency and a net decline in the impedance and corresponding inductance can be seen with increasing magnetization current. The impedances at 500 $\mathrm{Hz}$ are governed almost entirely by the reactances, and thus the single curves are given to represent both impedances and inductances.

Although these experimental results are by no means conclusive or even generalizable to most machines, they do demonstrate that the desired saturation-induced effects exist for at least one machine design and thus, at the very least, may be obtainable in other machines by appropriate design if necessary. One immediately apparent consideration is that in

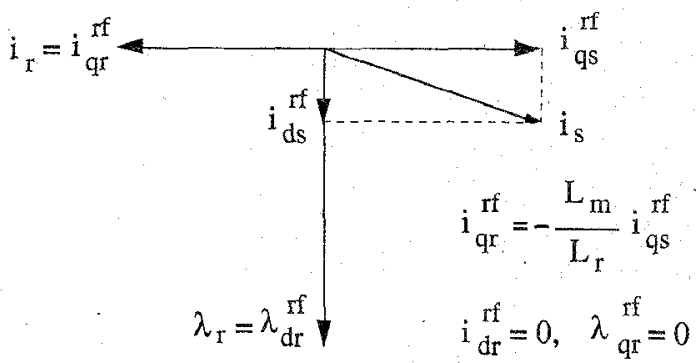

Fig. 6. Fundamental component current and flux vectors in the rotor flux reference frame under steady-state loaded conditions.

larger machines, higher surface current densities will tend to increase the localized saturation and thus impact the stator transient inductance to a greater extent than measured in Fig. 7(a).

\section{B. Closed Rotor Slot Machine}

The same measurements as above were conducted on a 10hp induction machine (Motor \#2 in Appendix) with closed rotor slots. The results are plotted in Fig. 8(a) and (b). Compared to the semiclosed slot machine of similar rating, the slot bridges of the closed rotor slots greatly add to the stator transient inductance.

Saturation of the slot bridges due to both induced-rotor currents during loading [Fig. 8(a)] and main flux [Fig. 8(b)] severely impact the stator transient inductance. Induced rotor currents are seen to drive the slot bridges deeper into saturation 


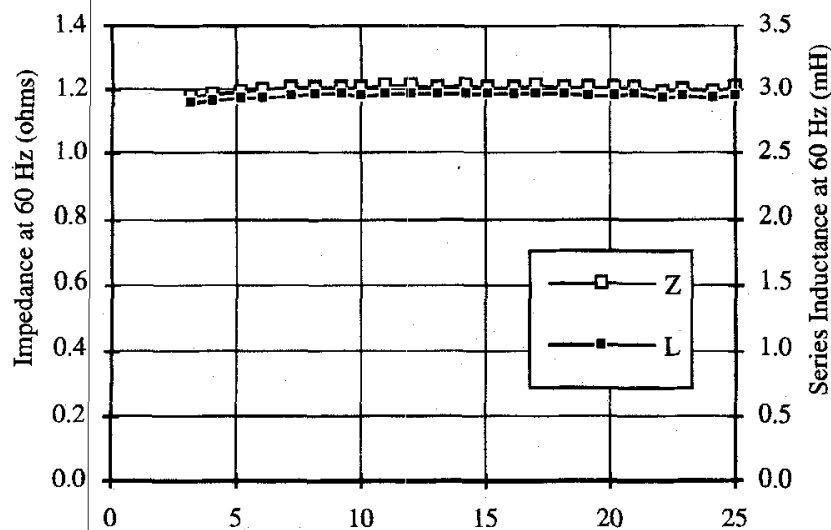

(a)

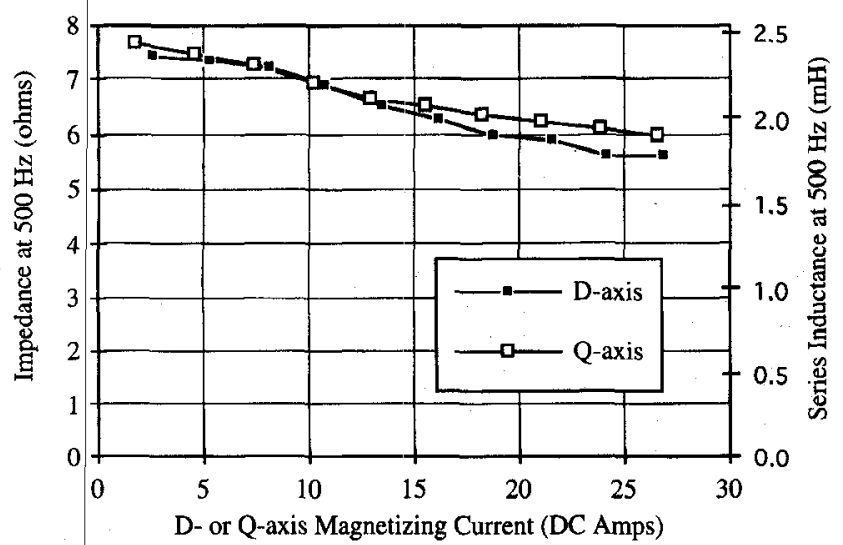

(b)

Fig. 7. Measured. (a) $60-\mathrm{Hz}$ locked-rotor impedance magnitude $(Z)$. and series inductance $(L)$. (b) $500-\mathrm{Hz} d$-axis locked-rotor impedance magnitude as a function of dc magnetizing current for machine with semiclosed rotor slots (Motor \#1 in Appendix, rated current $\approx 20 \mathrm{~A}$ rms, rated magnetizing current $\approx 10 \mathrm{~A}, 500-\mathrm{Hz}$ current $\approx 0.3 \mathrm{~A} \mathrm{rms}$ ).

than the main flux. At rated flux levels $(\approx 10$-A magnetizing current) and rated loading ( $\approx 24-\mathrm{A} \mathrm{rms})$, the stator transient inductance is most influenced by the loading. Thus for this machine, provided sufficient saliency was present, the rotor current vector would tend to be tracked rather than the main flux vector except at light loading.

\section{Flux Estimation for Field ORIENTATION in OPEn AND Semiclosed Slot Machines}

The experimental results demonstrated that a trackable saliency aligned with the main flux can exist in semiclosed slot machines. The precise alignment of the saliency relative to the stator and rotor flux was not determined. For field oriented control, knowledge of the particular flux vector that is tracked is important. As the alignment will vary with machine design and operating conditions, a universal means of utilizing the tracked saliency for obtaining field oriented control independent of alignment is attractive.

\section{A. Saliency Tracking with Model-Based Flux Estimation}

Although saliency tracking provides flux angular position information, it does not directly provide flux magnitude in-

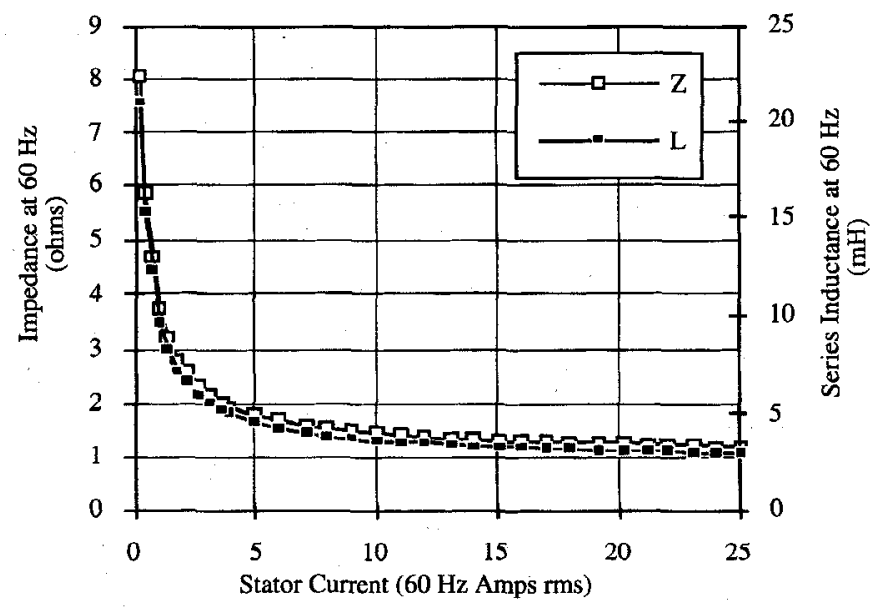

(a)

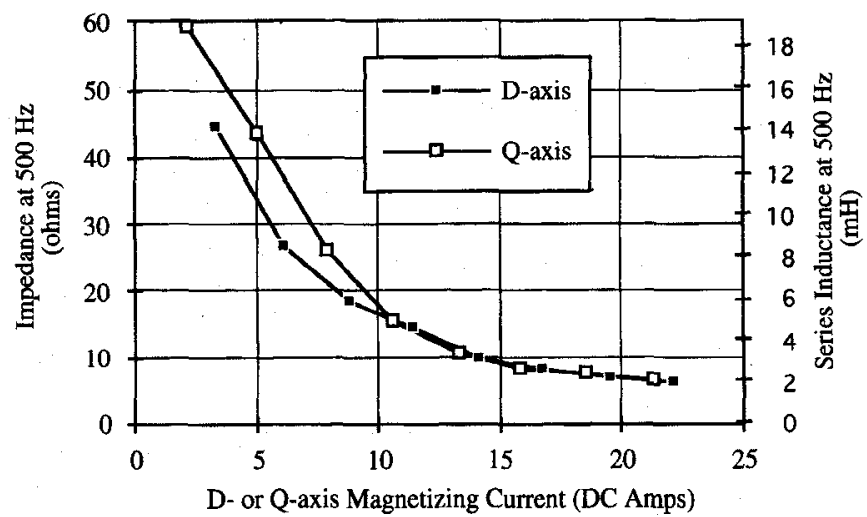

(b)

Fig. 8. Measured. (a) $60-\mathrm{Hz}$ locked-rotor impedance magnitude $(Z)$ and series inductance $(L)$. (b) $500-\mathrm{Hz} d$-axis locked-rotor impedance magnitude as a function of dc magnetizing current for a machine with closed rotor slots (Motor \#2 in Appendix, rated current $\approx 24 \mathrm{~A}$ rms, rated magnetizing current $\approx 10 \mathrm{~A}, 500-\mathrm{Hz}$ current $\approx 0.17 \mathrm{~A} \mathrm{rms}$ ).

formation also necessary for field orientation. Concepts from the "universal field oriented controller" in [8] can be borrowed to develop a combined saliency-tracking and model-based flux estimation approach providing complete rotor flux information for an arbitrary saliency alignment.

Equations describing the rotor flux in a synchronous reference frame aligned with an arbitrary flux vector can be derived by introducing an arbitrary turn ratio a in a similar manner as that presented in [8]:

$$
\begin{aligned}
& \hat{\lambda}_{d r}^{a}=\frac{1}{1+\hat{\tau}_{r} p}\left(\hat{L}_{m} i_{d s}^{a}-\hat{\omega}_{s} \hat{\sigma}_{a} \hat{\tau}_{r} a \hat{L}_{r} i_{q s}^{a}\right) \\
& \hat{\lambda}_{q r}^{a}=-\hat{\sigma}_{a} a \hat{L}_{r} i_{q s}^{a}
\end{aligned}
$$

where

$$
\hat{\omega}_{s}=\frac{a \hat{L}_{r}\left(1 / \hat{\tau}_{r}+\hat{\sigma}_{a} p\right) i_{q s}^{a}}{\hat{\lambda}_{d r}^{a}}
$$

and

$$
\hat{\sigma}_{a}=1-\frac{\hat{L}_{m}}{a \hat{L}_{r}} .
$$




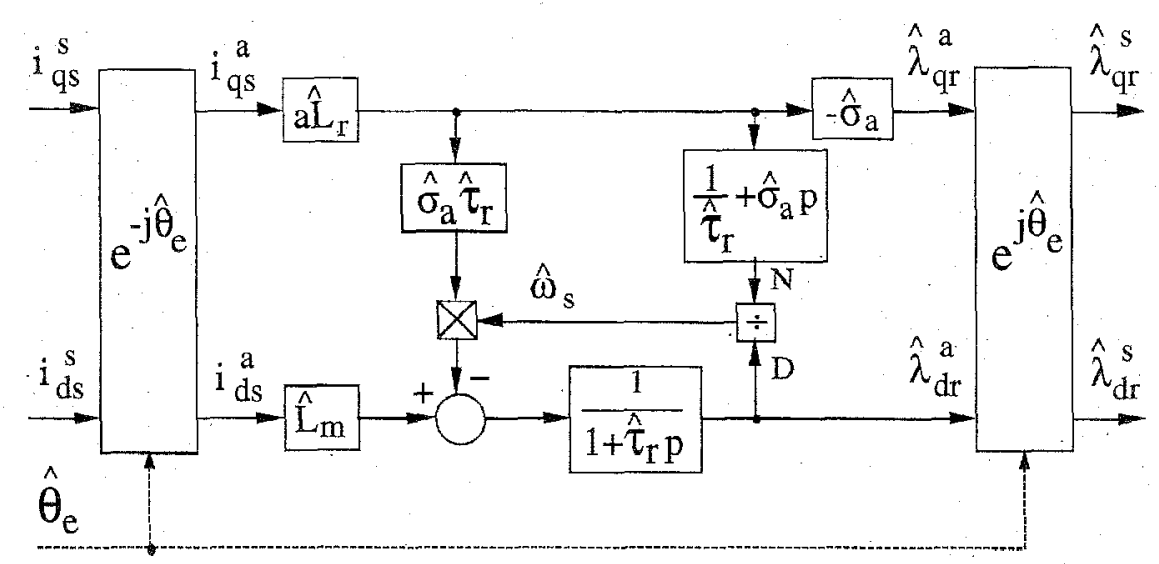

Fig. 9. Universal current model (UCM) in an arbitrary synchronous reference frame utilizing measured stator current and tracked saliency angle to yield the estimated rotor flux in the stationary frame.

TABLE I

Tuming of Turn Ratio for Specific Saliency Alignment

\begin{tabular}{|c|c|c|c|}
\hline $\begin{array}{c}\text { Alignment of } \\
\text { Saliency }\end{array}$ & Turn Ratio & $a \hat{L}_{r}$ & $\begin{array}{c}\text { Leakage Coef. } \\
\hat{\sigma}_{a}\end{array}$ \\
\hline rotor flux & $a=\hat{L}_{m} \hat{L}_{r}$ & $\hat{L}_{m}$ & 0 \\
\hline airgap flux & $a=1.0$ & $\hat{L}_{r}$ & $1-\hat{L}_{m} \hat{L}_{r}$ \\
\hline stator flux & $a=\hat{L}_{s} \hat{L}_{m}$ & $\hat{L}_{s} \hat{L}_{r} / \hat{L}_{m}$ & $1-\hat{L}_{m} 2 /\left(\hat{L}_{s} \hat{L}_{r}\right)$ \\
\hline
\end{tabular}

Equations (11)-(14) characterize a "current model" flux estimator similar to the current models in [1] and [4]. The stator current measured in the stationary reference frame can be transformed to the synchronous reference frame of the saliency via the estimated saliency position, $\hat{\theta}_{e}$. The estimated rotor mux in the saliency frame is then calculated using (11)-(14), and transformed back to the stator reference frame for use in direct field orientation. This "universal current model" (UCM) is shown in Fig 9.

Compared to the current models in [1] and [4] that utilize measured stator current and rotor position or velocity, the UCM sensitivity to the estimated rotor resistance is drastically reduced. The rotor resistance estimate only impacts the flux estimate during transients and via the cross-coupling when the saliency is other than rotor flux oriented. The estimated magnetizing inductance still directly impacts the magnitude of the estimated rotor flux.

The UCM requires that the turn ratio $a$ be properly tuned such that (11)-(14) correctly correspond to the saliency alignment given by $\hat{\theta}_{e}$. The value of $a$ as a function of saliency alignment is listed in Table I. For example, if a tracked saliency is more closely aligned with the stator flux, $a$ would be $>1.0$ and approach the value $L_{s} / L_{m}$. The optimal value of $a$ can be fixed a priori to drive implementation for a given machine design, or can be dynamically adjusted with operating condition to ensure correct alignment.

As expected, with $a=\hat{L}_{m} / \hat{L}_{r}$ and $\hat{\theta}_{e}$ equal to the rotor flux angle, the UCM in Fig. 9 reduces to the simple and familiar rotor flux frame model with complete decoupling between axes.
A similar UCM can be readily derived for estimation of the stator flux.

\section{B. Saliency Tracking with Flux Magnitude Mapping}

The experimental results in Fig. 7(b) demonstrate that flux magnitude information is also present in the stator transient inductance. Instead of relying upon the estimated parameters of the current model, the magnitude of the stator transient inductance can be utilized via a mapping approach to directly provide the flux magnitude.

A magnitude "tracking" approach can be easily incorporated with the saliency tracking approach by utilizing the inherent information in the term $I_{i 0}$ of (7). Whereas $I_{i 1}$ characterizes the amount of spatial modulation, $I_{i 0}$ characterizes the "average" stator transient inductance.

Heterodyning the high-frequency signal currents by $\sin \omega_{i} t$ and $\cos \omega_{i} t$ in the form

$$
\beta=i_{q s i}^{s} \sin \omega_{i} t+i_{d s i}^{s} \cos \omega_{i} t
$$

yields

$$
\beta=I_{i 0}+I_{i 1} \cos \left[2\left(\theta_{e}-\omega_{i} t\right)\right] .
$$

Similar to (10), $I_{i 0}$ is isolated by low pass filtering

$$
\beta_{f}=L P F(\beta)=\hat{I}_{i 0} .
$$

From $\hat{I}_{i 0}$ the inductance magnitude can be obtained by mapping. The approach is illustrated in Fig. 10. Similar to the saliency tracking, the magnitude information contained within $\hat{I}_{i 0}$ may more closely correlate to either the stator or rotor flux, 


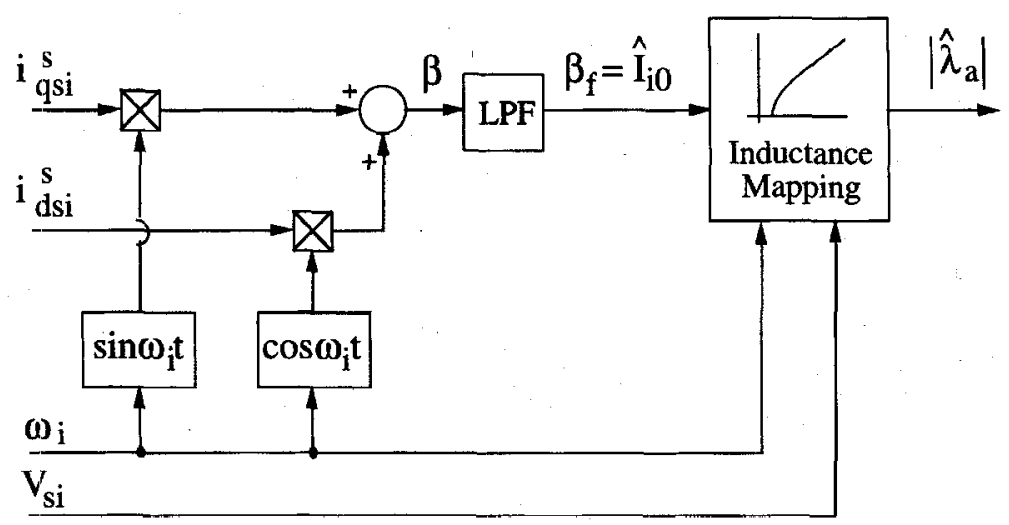

Fig. 10. A heterodyning scheme with inductance mapping to provide flux magnitude information from the high-frequency signal injection.

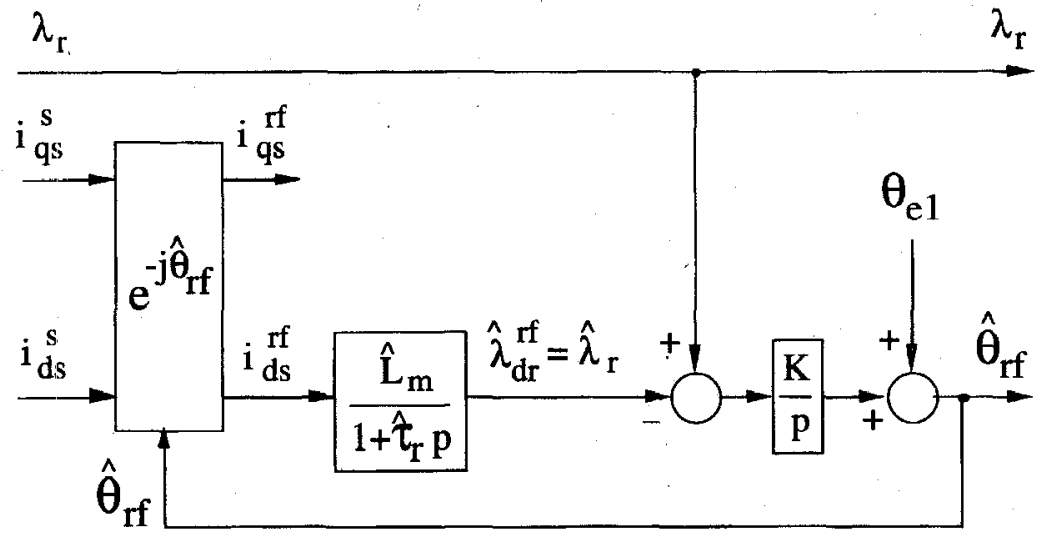

Fig. 11. A closed-loop tracking scheme to obtain rotor flux position information given rotor flux magnitude and machine parameters, with the fundamental current excitation angle, $\theta_{e 1}$, added to improve tracking.

or in between. With the addition of fundamental component stator current feedback, if necessary, the mapping can be designed to directly yield rotor or stator flux magnitude as desired.

\section{Magnitude Tracking Only}

Since the addition of a machine model enabled flux magnitude information to be obtained from known flux position (Fig. 9), it follows that a machine model could also be developed to enable flux position information to be obtained from known flux magnitude. A simple low-performance scheme utilizing the flux magnitude from Fig. 10 is shown in Fig. 11. This approach works because flux orientation errors caused by flux position estimate errors were shown in [1] to be compensated for by flux regulation if flux magnitude was accurately known. However, this scheme inherently lags since the magnitude information lags. The performance dynamics of this approach for field orientation would be correspondingly sluggish.

\section{FluX EstimATION FOR FIELD} Orientation in Closed Slot Machines

The experimental results in Fig. 8 indicate that the saliency tracking scheme in Fig. 1 would tend to track the rotor current vector in a closed rotor slot machine under loaded conditions, rather than a flux vector. Thus direct knowledge of flux would not be obtained. However, under steady-state conditions, the rotor flux and rotor current vectors are orthogonal as illustrated in Fig. 6. Some knowledge of the rotor flux angle thus may still be obtainable by tracking the rotor current vector. Unfortunately, orthogonality is lost during transient operation.

As shown in Fig. 12(a), a change in $d$-axis stator current will induce a transient $d$-axis rotor current to maintain constant flux, thereby shifting the rotor current vector and the corresponding rotor slot bridge saturation vector that is being tracked. If the controller assumes the rotor flux angle is always orthogonal to the rotor current vector, then the newly estimated rotor flux angle will be incorrect as shown in Fig. 12(b). The controller will attempt to maintain the desired stator current vector based upon the new incorrectly estimated flux angle, driving additional current along the true $d$-axis. Thereby inducing more transient $d$-axis rotor current. The system thus appears to be at an unstable equilibrium at steady state.

A means of utilizing a tracked rotor current vector for achieving field oriented control is not readily apparent.

\section{EXPANDING OPERATING Limitations}

Robust tracking of saturation-induced saliencies may require operation at flux levels that are considerably higher than 


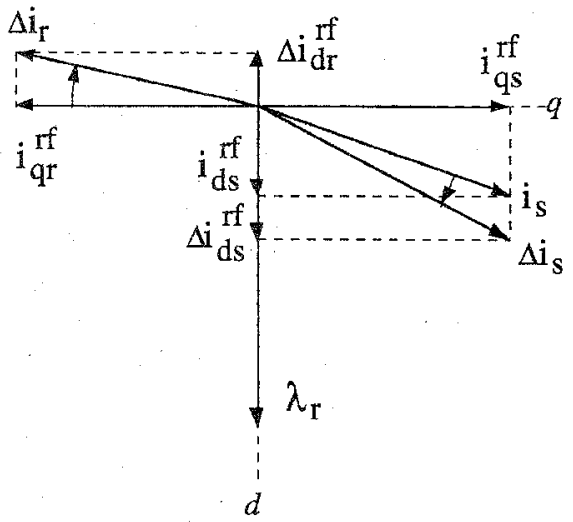

(a)

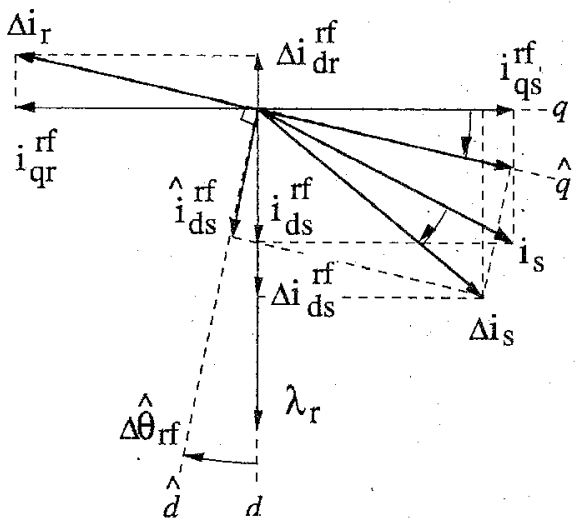

(b)

Fig. 12. Current and rotor flux space vectors as defined in the rotor flux reference frame illustrating: (a) Resulting transient $d$-axis rotor current in response to an increase in $d$-axis stator current. (b) Resulting error in the estimated rotor flux angle if the rotor flux is assumed orthogonal to the rotor current vector.

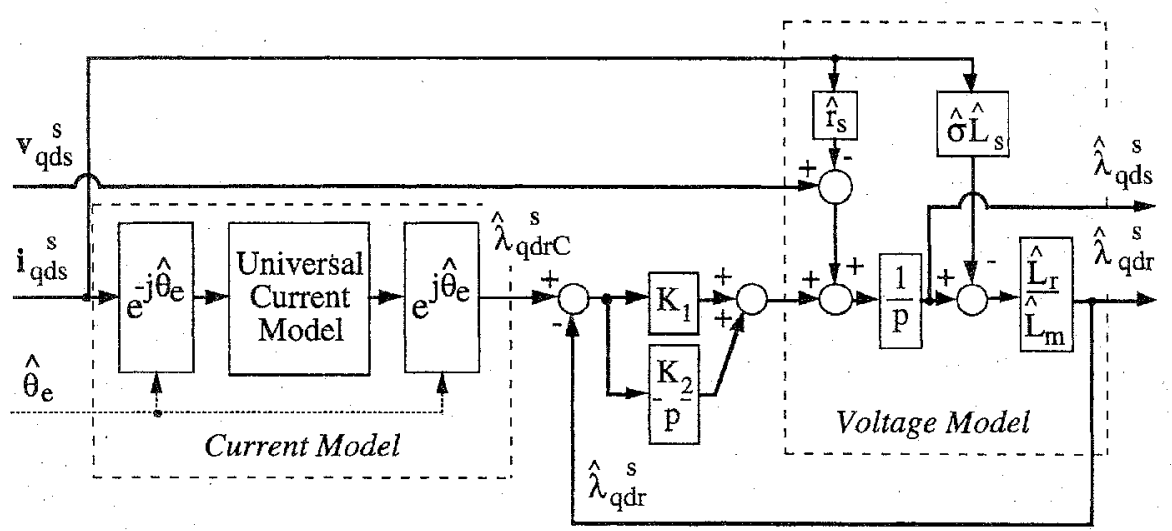

Fig. 13. Closed-loop stator/rotor flux observer (CLFO) for wide-speed range transducerless direct field orientation (DFO) utilizing the UCM with saliency tracking for low and zero frequency operation and the back-EMF-based voltage model for high-frequency operation.

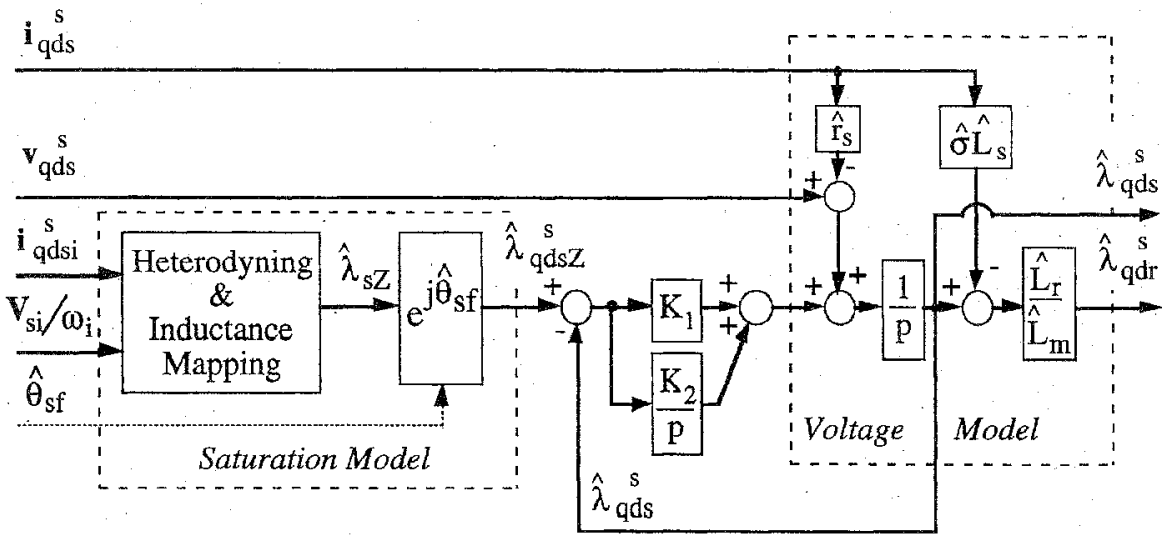

Fig. 14. CLFO for wide-speed range transducerless DFO utilizing flux magnitude mapping with saliency tracking for low and zero frequency operation and the voltage model for high speed operation. The saliency and magnitude information are depicted to yield estimated stator flux in this figure.

normal or rated. The maximum operational speed will then be limited by core loss and/or stator voltage. Field-weakened operation is obviously not possible. Furthermore, generation of the high-frequency signal excitation by the inverter requires the inverter to remain in a PWM or pulse density modulation mode.

Therefore, to obtain wide speed range operation including field weakening, the saliency tracking scheme must be com- bined with a scheme suitable for high-speed operation (as also proposed in [7]). The topology of the closed-loop flux observers in [1] and [4] is ideally suited, enabling smooth transition between the tracking scheme and the voltage model. The UCM of Fig. 9 can be incorporated with a back-EMFbased voltage model as shown in Fig. 13. Alternatively, the inductance mapping scheme of Fig. 10 can be incorporated as shown in Fig. 14. 


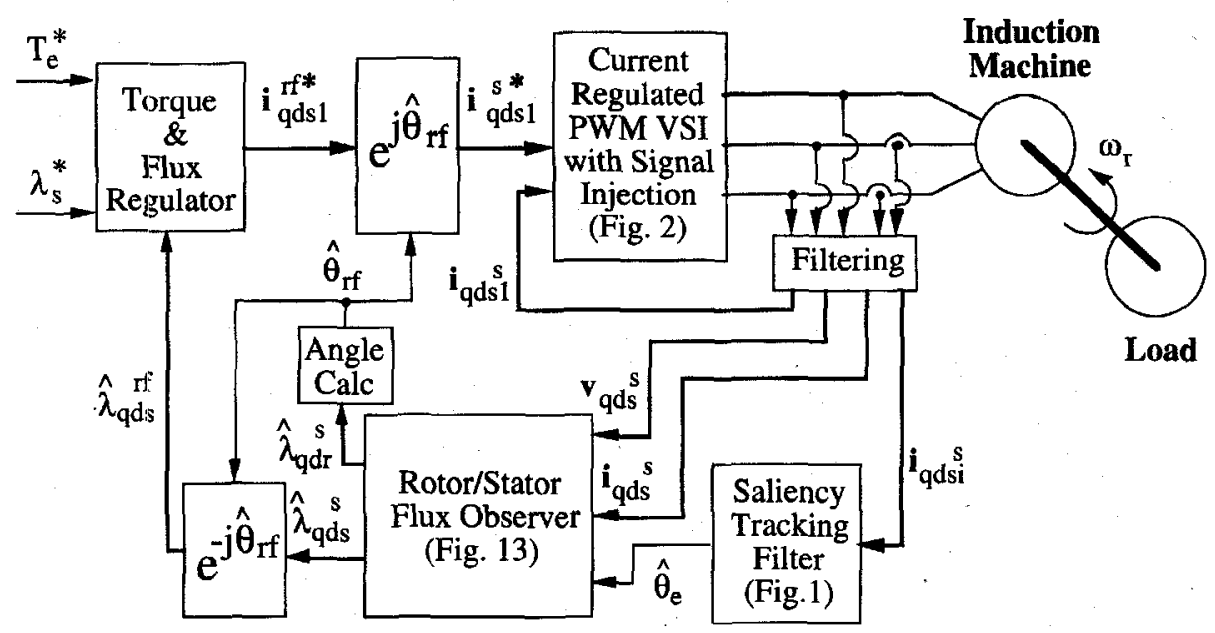

Fig. 15. Simulated implementation of a direct field oriented, transducerless, torque-controlled drive utilizing saturation-induced saliencies.

One significant limitation of this and any saturation-based control scheme, however, is the inherent dependency upon maintaining saturation. If control is interrupted during operation, the induction machine will likely leave the saturated state. Estimation via saliency tracking may then not be recoverable without coming to a complete stop. When integrated with the voltage model as in Fig. 13 or 14, this limitation is present only at zero and low frequencies.

This limitation is not present in transducerless systems that track permanent saliencies such as in induction motors with spatial modulations introduced in the rotor leakage inductance [2], or in permanent magnet motors with constant fields or inherent rotor saliency [3].

\section{SimULATION RESULTS}

The performance of a transducerless system based upon the tracking of saturation-induced saliencies was evaluated via simulation. Fig. 15 shows the system block diagram with torque and stator flux command inputs. Speed regulation was not simulated, although the concepts presented in this paper can certainly be extended to include speed estimation. Speed was therefore assumed to be externally regulated.

The rotor/stator flux observer (CLFO) consisted of the UCM and the voltage model as shown in Fig. 13. The direct field oriented system was rotor-flux-oriented but stator-fluxregulated as described in [1]. The 7.5-hp induction motor with semiclosed rotor slots (Motor \#1 in Appendix) was chosen for the simulation. The motor was modeled with a saturationinduced stator-flux-oriented saliency with $d$ - and $q$-axis stator transient inductances varying as a function of flux magnitude similar to that measured for the motor and plotted in Fig. 7.

The simulated inverter utillized uniformly sampled, asymmetrical sine-triangle PWM switching at $5 \mathrm{kHz}$ with $2 \mu \mathrm{s}$ deadtime. The deadtime was compensated during the calculation of switching periods based upon the current feedback. The controller sampling rate was $10 \mathrm{kHz}$.

The balanced three-phase injected signal was $10 \mathrm{~V} L-L$ rms at $555 \mathrm{~Hz}$, resulting in a signal current of $\approx 0.88 \mathrm{~A}$ rms
(4.4\% rated) at $115 \%$ rated stator flux. The current feedback resolution was limited to $0.024 \%$ (1/4096).

A second-order bandpass filter with the center frequency set to the signal frequency and a $100-\mathrm{Hz}$ passband was selected for isolation of the measured signal currents (Fig. 2). The bandpass filter introduced a phase shift in the isolated signal currents as a function of the saliency angular velocity, which created a small but noticeable error in the tracked saliency angle and required compensation based upon $\hat{\omega}_{e}$ from Fig. 1 .

A $300-\mathrm{Hz}$ fourth-order low-pass filter suppressed the twice signal frequency components after heterodyning (9)-(10). The closed-loop tracking filter gains set a small signal bandwidth of $\approx 50 \mathrm{~Hz}$ for tracking the saturation-induced saliency.

A $350-\mathrm{Hz}$ fourth-order low-pass filter removed most of the signal current component from the current feedback to the synchronous frame current regulator (Fig. 2). To further minimize disturbance of the injected signal voltage from the current regulator, the bandwidth of the current regulator was set to a relatively low value of $60 \mathrm{~Hz}$. Synchronous voltage feedfoward was added to improve the current tracking.

Fig. 16(a)-(h) demonstrates start-up from standstill and transition between saliency tracking/UCM and voltage-modelbased flux estimation. While at standstill and the saliency tracking disabled, the motor was driven into saturation with a $115 \%$ rated stator flux command. At time $1.0 \mathrm{~s}$, the saliency in the stator transient inductances was sufficiently large to enable saliency tracking. At time $2.0 \mathrm{~s}, 100 \%$ rated torque was commanded followed by a ramped velocity profile. The torque ripple created by the signal injection is apparent in Fig. 16(b).

Fig. 16(e)-(h) shows the event sequence for transition between the saliency tracking/UCM and the voltage model. The sequencing was based on the excitation frequency calculated from the estimated stator flux from the CLFO, and is summarized below:

Max. freq. with UCM output enabled in CLFO $6 \mathrm{~Hz}$ Max. freq. with UCM calculation enabled $\quad 8 \mathrm{~Hz}$ Max. freq. with saliency tracking enabled $\quad 10 \mathrm{~Hz}$ Max. freq. with signal injection enabled $12 \mathrm{~Hz}$. 


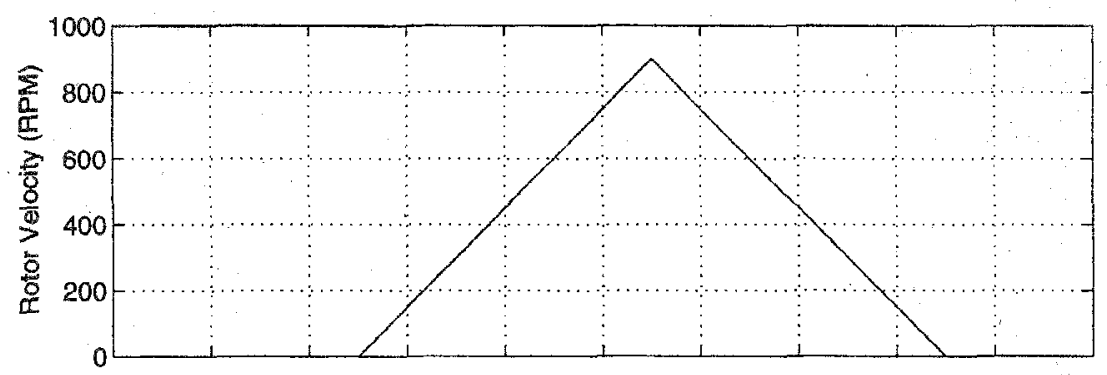

(a)

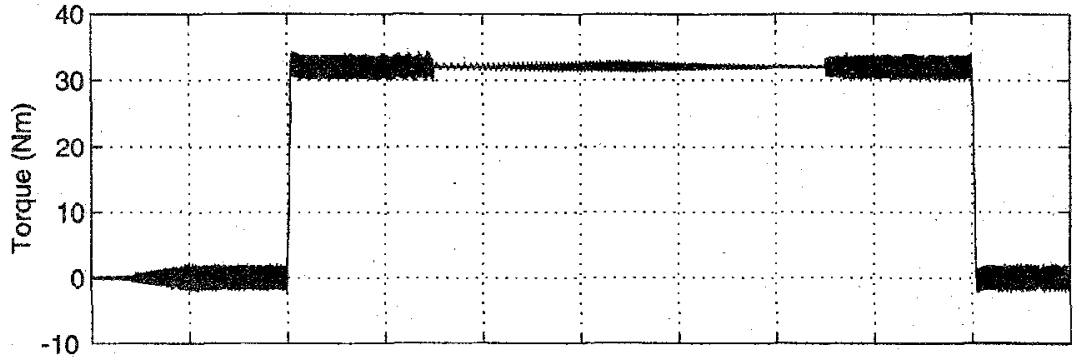

(b)

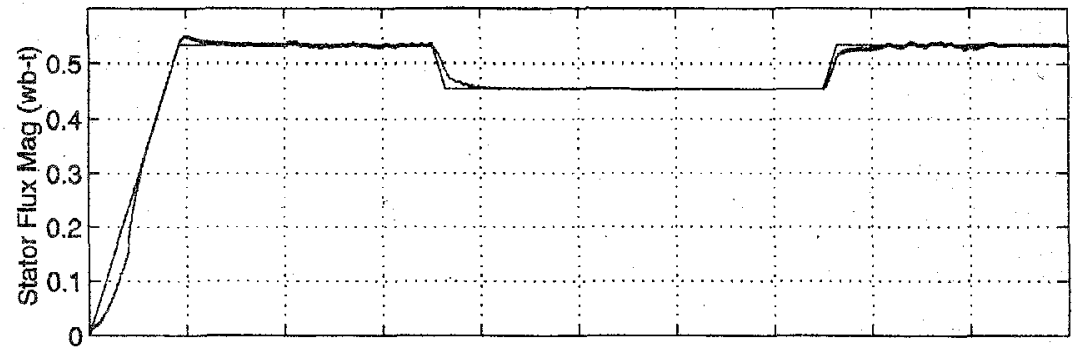

(c)

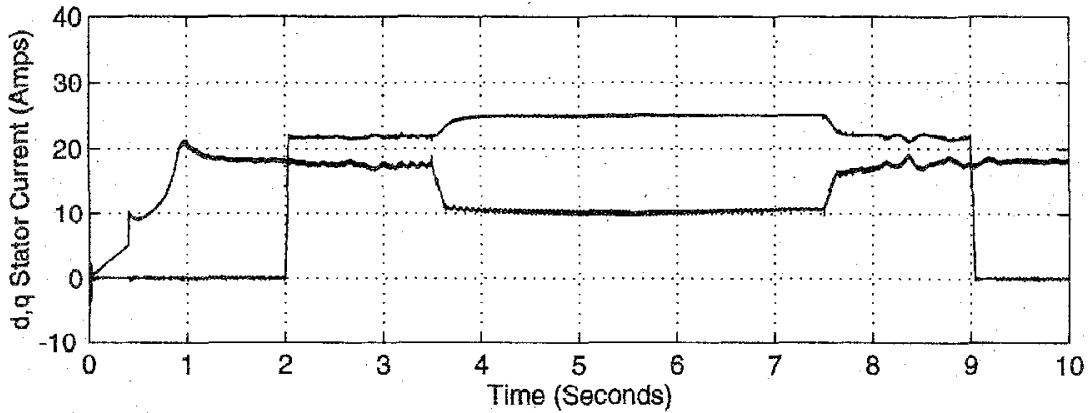

(d)

Fig. 16. Simulation results illustrating system startup with a ramped velocity profile, and $100 \%$ torque and $115 \%$ flux commands. (a) Rotor velocity (r/min). (b) Commanded and actual torque $(32 \mathrm{~N} \cdot \mathrm{m} \approx 100 \%)$. (c) Commanded and actual stator flux magnitude $(0.53 \mathrm{wb}-\mathrm{t} \approx 115 \%)$. (d) Commanded and actual $d$ - and $q$-axis stator currents in rotor flux frame $(\mathrm{A})$.

Above $6 \mathrm{~Hz}$ operation, the output of the CLFO was thus entirely from the voltage model. Simultaneous to the disabling of signal injection, the flux level was decreased to $100 \%$ rated.

Because the saliency is tracked independent of the polarity of the flux, it is possible for the tracking filter to lock onto the saliency $180^{\circ}$ out of phase with the true flux angle. This possibility mathematically exists because of the factor of 2 in (10). Therefore, after reestablishing saliency tracking during velocity ramp down, the tracked angle was compared with the flux angle from the voltage model. A factor of $\pi$ was added to the tracked angle if necessary before enabling the calculation and output of the UCM.

Sustained torque control of $150 \%$ rated at zero frequency with large resistance errors $\left(\hat{r}_{s}=0.5 r_{s}\right.$ and $\left.\hat{r}_{r}=0.5 r_{r}\right)$ is demonstrated in Fig. 17(a)-(e). After prefluxing the motor at standstill to $115 \%$ rated, the velocity was increased to the slip frequency corresponding to $150 \%$ torque. A torque command of $-150 \%$ was then commanded, at which point the excitation frequency became effectively zero. As shown, the resistance errors have almost negligible impact on the torque and flux 


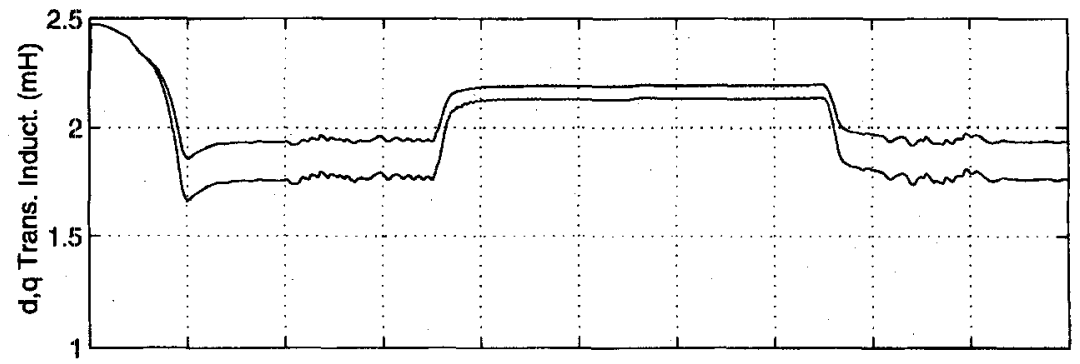

(e)

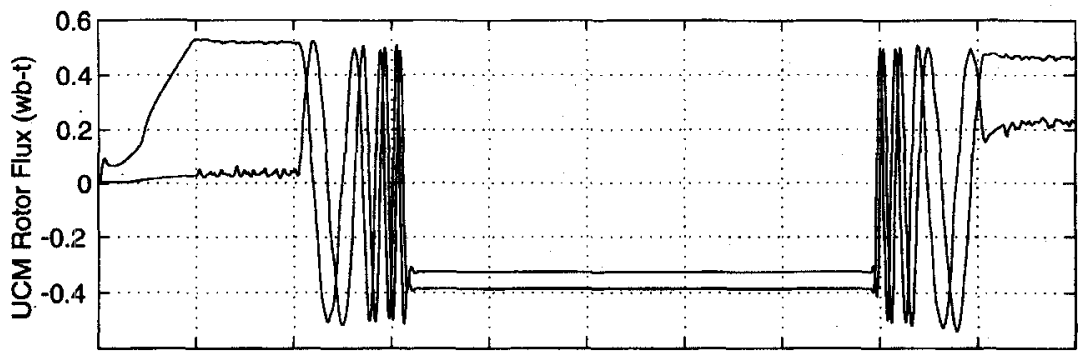

(f)

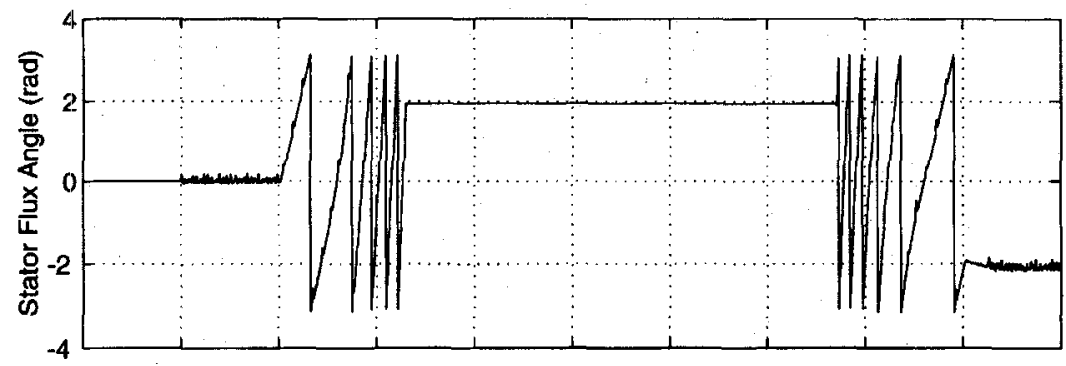

(g)

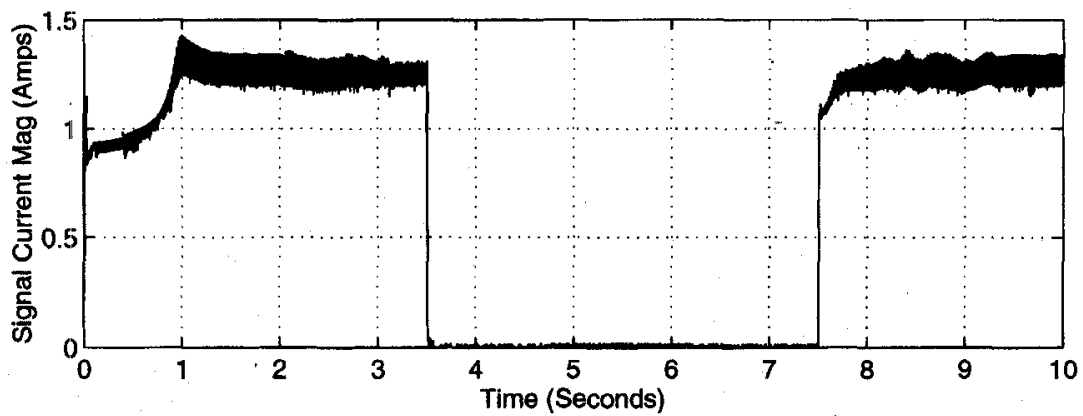

(h)

Fig. 16. (Continued). (e) $d$ - and $q$ - axis stator transient inductance illustrating saliency (mH). (f) Estimated rotor flux from UCM (wb-t). (g) Estimated stator flux angle as tracked (rad). (h) Signal current magnitude (A).

accuracy. The small error in the stator flux magnitude was caused by incorrect cross coupling in the stator-flux-aligned UCM due to the rotor resistance error.

Although a magnetizing inductance error would adversely affect the flux and torque accuracy, it would not directly impact the system robustness, provided that the machine was still sufficiently saturated to enable robust saliency tracking.

\section{APPLICATION TO PM AC MACHINES}

Like induction machines, the rotors of surface-mounted PM ac machines are magnetically smooth or nonsalient. With proper design such that the stator teeth and/or core are sufficiently saturated, a saturation-induced saliency can exist in the synchronous inductances. In the absence of rotor or field windings, the stator inductance seen at high frequencies is the synchronous inductance. Thus the saturation-induced saliency tracking scheme as proposed in Section II could be directly applied to surface-mounted PM machines.

\section{$\mathrm{X}$. Conclusions}

The tracking of saturation-induced saliencies present in the stator transient inductance of induction machines promises 


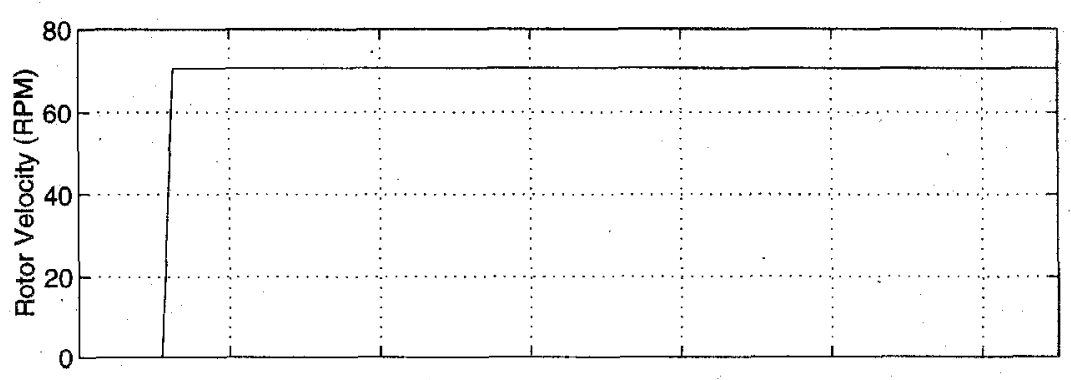

(a)

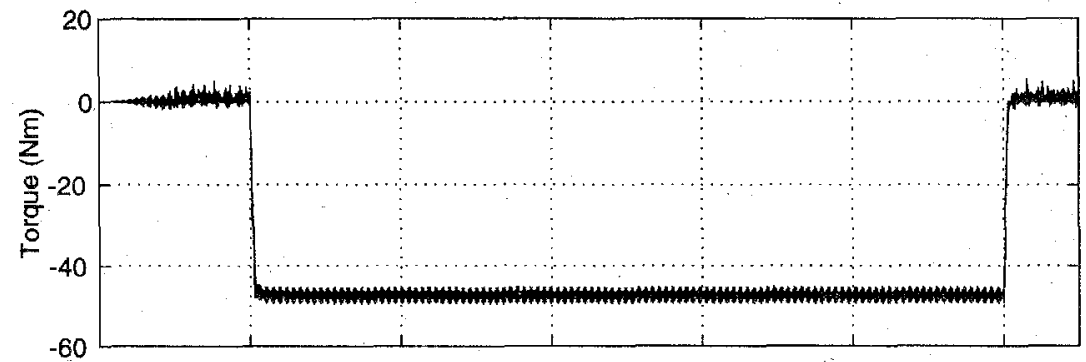

(b)

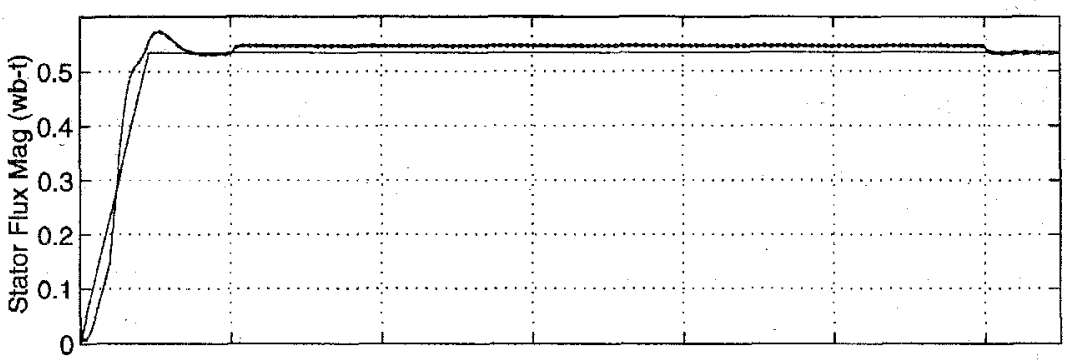

(c)

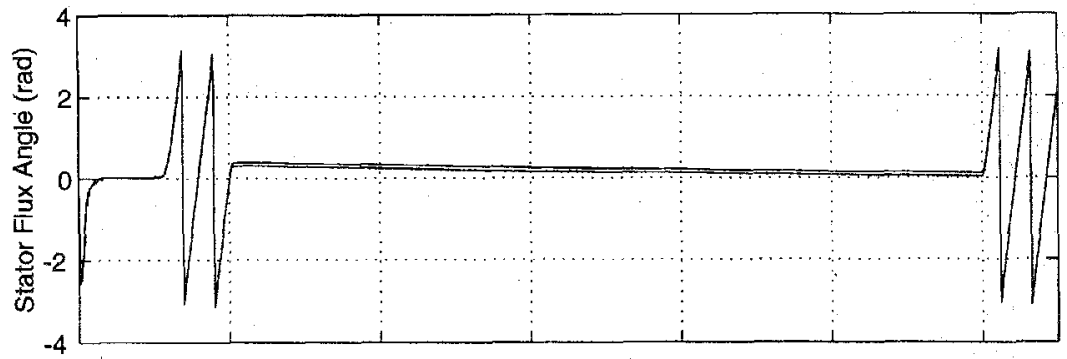

(d)

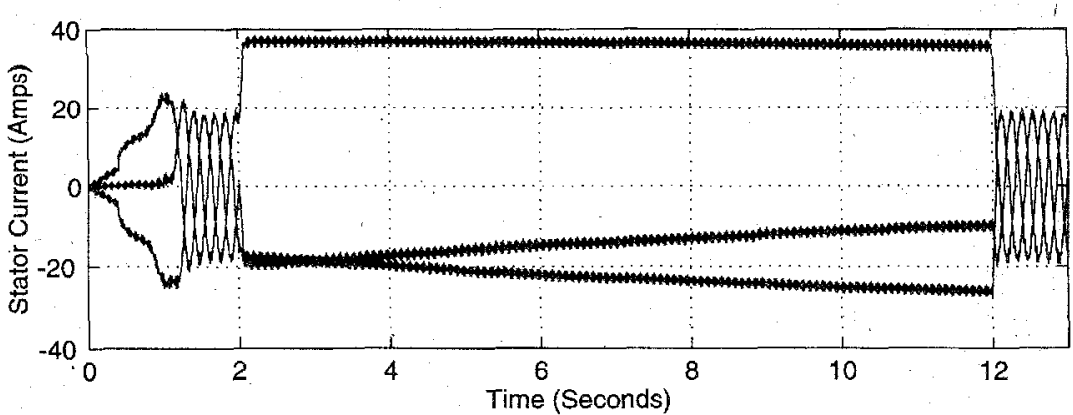

(e)

Fig. 17. Simulation results illustrating. $150 \%$ torque at sustained zero-frequency operation with large resistance errors: $\hat{r}_{s}=0.5 r_{s}$ and $\hat{r}_{r}=0.5 r_{r}$. (a) Rotor velocity ( $\mathrm{r} / \mathrm{min}$ ). (b) Commanded and actual torques (N.m). (c) Commanded and actual stator flux magnitudes (wb-t). (d) Actual and estimate (tracked) stator flux angles (rad). (e) Three-phase stator current including fundamental and signal (A). 
to be a viable and potentially attractive means of achieving transducerless field oriented control in certain applications requiring sustained zero and low-frequency operation. The best machine candidates appear to have open or semiclosed rotor slots, and are designed such that saturation of the main flux path has a much greater impact upon the stator transient inductance than localized saturation caused by load current.

The tracking scheme incorporates signal injection utilizing the same inverter that supplies the fundamental excitation, and demodulation consisting of heterodyning and a closed-loop tracking filter to provide a continuous flux position estimate. Additional flux magnitude information can be obtained via incorporating machine models or by direct mapping of the stator transient inductance magnitude. The scheme can be readily combined with the voltage model in a closed-loop observer topology for wide speed range field oriented control.

Simulation results demonstrated accurate and robust field oriented control at sustained zero frequency operation, during start-up from standstill, and during transitions at higher speeds between saliency-tracking and voltage model schemes.

\section{APPENDIX \\ TEST INDUCTION MACHINES}

Motor \#1: semiclosed rotor slots (Fig. 7)

Baldor, $7.5 \mathrm{hp}$, four-pole, Frame 284T, three-phase, 440/220 $\mathrm{V}, 10 / 20 \mathrm{~A}, 1725 \mathrm{r} / \mathrm{min}$.

Motor \#2: Closed rotor slots (Fig. 8)

Westinghouse TEE II, $10 \mathrm{hp}$, four-pole, Frame 215T, threephase, $460 / 230 \mathrm{~V}, 12.2 / 24.4 \mathrm{~A}, 1750 \mathrm{r} / \mathrm{min}$.

\section{REFEIRENCES}

[1] Jansen, P.L., Lorenz, R.D., and Novotny, D.W., "Observer-Based Direct Field Orientation: Analysis and Comparison of Alternative Methods", IEEE Trans. Ind. Appl., Vol. 30, no. 4, July/Aug. 1994, pp. 945-953.

[2] Jansen, P.L. and Lorenz, R.D., "Transducerless Position and Velocity Estimation in Induction and Salient AC Machines", IEEE Trans. Ind. Appl., Vol. 31, no. 2, Mar./Apr. 1995, pp. 240-247.

[3] Jansen, P.L., Corley, M., and Lorenz, R.D., "Flux, Position, and Velocity Estimation in AC Machines at Zero and Low Speed via Tracking of High Frequency Saliencies", Proc. EPE Conf., Seville, Spain, Sept. 1995.

[4] Jansen, P.L. and Lorenz, R.D., "Accuracy Limitations of Velocity and Flux Estimation in Direct Field Oriented Induction Machines", Proc. EPE Conf, Brighton, UK, Sept. 1993.

[5] Schroedl, M., "Operation of the Permanent Magnet Synchronous Machine Without a Mechanical Sensor", Proc. Int. Conf. on Power Electronics and Variable Speed Drives, IEE, London, July 1990, pp. 51-56.

[6] Schroedl, M., "Sensorless Control of Induction Motors at Low Speed and Standstill", Proc. ICEM, Boston, MA, Aug. 1990, pp. 863-867.
[7] Schroedl, M., Hennerbichler, D., and Wolbank, T.M., "Induction Motor Drive for Electric Vehicles without Speed- and Position Sensors", Proc. EPE Conf., Sept. 1993, pp. 271-275.

[8] De Doncker, R.W. and Novotny, D.W., "The Universal Field Oriented Controller", IEEE Trans. on Ind. Appl., Vol. 30, no. 1, Jan./Feb. 1994, pp. $92-100$

[9] Cuzner, R.M., Lorenz, R.D., and Novotny, D.W., "Application of NonLinear Observers for Rotor Position Detection on an Induction Motor Using Machine Voltages and Currents", Proc. IEEE-IAS Annual Meeting, Oct. 1990 , pp. 416-421.

[10] Jansen, P.L., The Integration of State Estimation, Control, and Design for Induction Machines, Ph.D. Dissertation, Dept. of Electrical and Computer Engineering, University of Wisconsin-Madison, 1993.

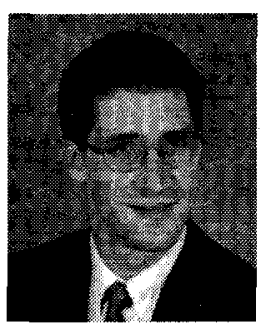

Patrick L. Jansen received the B.S., M.S., and Ph.D. degrees in electrical engineering from the University of Wisconsin, Madison, in 1985, 1987, and 1993, respectively.

From 1987 to 1989 , he was a development engineer with Machine Dynamics Pty. Ltd., Victoria, Australia, and later the CSIRO, Division of Applied Physics, NSW, Australia. From 1994 to 1995, he was a staff engineer at MK Rail Corp., Boise, ID, where he was involved inthe development of $\mathrm{AC}$ propulsion systems for high-horsepower locomotives. He is presently with the Power Controls Program, General Electric Corporate Research and Development Center, Schenectady, NY.

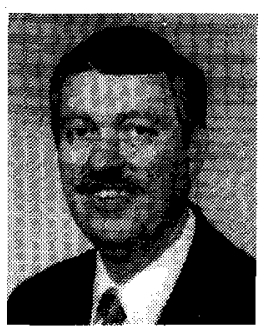

Robert D. Lorenz (S'83-M'84-SM'91) received the B.S., M.S., and Ph.D. degree from the University of Wisconin, Madison in 1969, 1970, and 1984 respectively.

Since 1984, he has been a member of the faculty, University of Wisconsin, where he is Professor of mechanical engineering and of electrical and computer engineering. In this position he acts as Associate Director of the Wisconsin Electric Machines and Power Electronics Consortium and as Co-Director of the Advanced Automation and Robotics Consortium. He was a Visiting Research Professor in the Electrical Drives Group of the Catholic University of Leuven, Leuven, Belgium, and in the Electrical Drives Institute of the Technical University of Aachen, Germany, in the summers of 1989 and the summers of 1987 and 1991, and 1995 respectively. In 1969 and 1970, he did the master thesis research at the Technical University of Aachen, West Germany. From 1972 to 1982, he was a member of the research staff, Gleason Works, Rochester, NY. His current research interests include sensor integrated electromagnetic actuator technologies, real-time digital signal processing and estimation techniques, and ac drive and high-precision machine control technologies.

Dr. Lorenz is currently Chair of the IEEE IAS Awards Department and past Chairman of the IEEE IAS Industrial Drives Committee. He is a member of the Industrial Automation and Control Committee, the Electrical Machines Committee, and the Industrial Power Converter Committee. He is also an active consultant to many organizations and is a Registered Professional Engineer in the States of New York and Wisconsin. He is a member of the American Society of Mechanical Engineers, the Instrument Society of America, and the Society of Photo-Optical Instrumentation Engineers. 